\title{
Enhancing Visibility of Vendor Accessibility Documentation
}

\begin{abstract}
With higher education increasingly being online or having online components, it is important to ensure that online materials are accessible for persons with print and other disabilities. Libraryrelated research has focused on the need for academic libraries to have accessible websites, in part to reach patrons who are participating in distance-education programs. A key component of a library's website, however, is the materials it avails to patrons through vendor platforms outside the direct control of the library, making it more involved to address accessibility concerns. Librarians must communicate the need for accessible digital files to vendors so they will prioritize it. In much the same way as contracted workers constructing a physical space for a federal or federally funded agency must follow ADA standards for accessibility, so software vendors should be required to design virtual spaces to be accessible. A main objective of this study was to determine a method of increasing the visibility of vendor accessibility documentation for the benefit of our users. It is important that we, as service providers for the public good, act as a bridge between vendors and the patrons we serve.
\end{abstract}

\section{INTRODUCTION}

The World Wide Web was developed late in 1989 but reached the public sector the following year and quickly gained prominence. ${ }^{1}$ Around this same time (1990), the Americans with Disabilities Act (ADA) was also passed, so when it was written the role of the web had yet to take shape. Websites and online content, while not included specifically in the ADA, have been increasingly emphasized when institutions examine the accessibility of their resources for persons with disabilities. More recent legislation, as well as legal-settlement agreements (including with colleges and universities), have included-and even emphasized-the importance of accessible online content. Researchers have argued that in requiring facilities to be accessible, ADA must include digital accessibility. ${ }^{2}$

With higher education increasingly being online or having online components, it is important to ensure that online materials are accessible for persons with print and other disabilities, many of whom may have received more extensive support in primary and secondary schools. Unless accessibility is pursued with purpose, the level of education and educational materials available for students with disabilities will be severely limited. ${ }^{3}$

\section{LITERATURE REVIEW}

\section{Legislation and Existing Guidelines}

Equal access to information for all patrons is a foundational goal of libraries. In higher education, accessible information and communications technology allows users of all abilities to focus on learning without undue burden. ${ }^{4}$ Colleges and universities are required by law to provide

Samuel Kent Willis (samuel.willis@wichita.edu) is Assistant Professor and Technology Development Librarian and Faye 0’Reilly (faye.oreilly@wichita.edu) is Assistant Professor and Digital Resources Librarian at Wichita State University. 
reasonable accommodations to allow an individual with a disability to participate fully in the programs and activities of the university. According to Title II of ADA, discrimination on the basis of disability by any state or local government and its agencies is strictly prohibited. ${ }^{5}$ Section 504 of the Rehabilitation Act of 1973 also prohibits discrimination on the basis of disability by any program or activity receiving federal assistance. ${ }^{6}$ The Department of Education stated, "Public Educational institutions that are subject to Education's Section 504, regulations because they receive Federal financial assistance from us are also subject to the Title II regulations because they are public entities (e.g., school districts, State educational agencies, public institutions of vocational education and public colleges and universities)." 7 This piece of legislation usually manifests itself in the physical learning space-wheelchair ramps, braille textbook options, interpreters, and more-but finds little application in the digital spaces of a university, especially in the library's online research presence. This is an alarming revelation; much higher learning today takes place in an online environment, and inaccessible library resources are a contributing factor to challenges in higher education faced by users with disabilities.

To be considered accessible, a digital space, such as a website, online-learning management system, or a research discovery layer, and any Word documents, PDFs, and multimedia presented therein, should be formatted in such a way that it is compatible with assistive technologies, such as screen-reading software. A website should also be navigable without a mouse using visual or auditory clues. Content on a website ought to be clearly and logically organized, with skip navigation links to bypass to the page's main content. Images should have alternative text descriptions, known as "alt text," that is brief and informative, describing the content and role of the image. Links should likewise have clear descriptions of the target page. These and similar considerations aim to help persons with impairments that may make reading a monitor or screen difficult. $^{8}$ Digital spaces like a research database are considered electronic information technology (EIT). EIT is defined as "information technology and any equipment or interconnected system or subsystem of equipment that is used in the creation, conversion or duplication of data or information."9 Recently this terminology has been converted to information and communications technology (ICT) as per the final rule updating Section 508 in early 2017, but the essence of what it means remains unchanged. ${ }^{10}$

Legislation regarding digital accessibility exists, specifically Section 508 of the Rehabilitation Act of 1973, but only federal agencies and institutions receiving federal aid are required to abide by these statutes. Lawmakers considered technology as a growing part of daily life in 1998 and amended the Rehabilitation Act with Section 508, requiring federal agencies to make their ICT accessible to people with disabilities. ${ }^{11}$ In 2017, these standards were updated with a final rule that modernized guidelines for accessibility of future ICT. ${ }^{12}$ Any research databases or other applications used by college and university libraries to facilitate online learning would be considered ICT and thereby subject to Section 508 requirements. It is evident that libraries not only have legal reasons to comply with Section 508, but ethical reasons as well because making library collections and services universally available is a core value of the library community. ${ }^{13}$

In addition to legislation, the World Wide Web Accessibility Initiative (WAI) created the Web Content Accessibility Guidelines (WCAG) in 1999 in response to the growing need for web accessibility and to promote universal design. These standards created for web-content creators and web-tool developers are continually updated as new technologies and capabilities emergewith version 2.0 being released in 2008-and apply specifically to web content and design. Many 
of these guidelines were absorbed by the 2017 refresh of Section 508 of the Rehabilitation Act of 1973. ${ }^{14}$ With fourteen guidelines assigned priority levels $1-3$, WCAG 2.0, and subsequent revisions to date, offer three levels of conformance with digital-accessibility guidelines: Level A, the most basic level, meaning all mandatory level 1 guidelines are met; Level AA, meaning priority levels 1 and 2 are met; and Level AAA, meaning priority levels 1-3 are met. These conformance levels are important because many ICT vendors will make their claims to conformance with WCAG standards by using provided WAI icons or using statements that refer to the level of conformance. ${ }^{15}$

WCAG 2.0 guidelines alone are not enough to determine fully if a website or other digital content is truly accessible. It partly depends on it having an intuitive layout for a variety of users, which can only be achieved through usability testing. ${ }^{16}$ It is crucial that librarians understand what is required for a product or service to be considered accessible, and a firm grasp of WCAG 2.0 and its conformance levels will enrich a librarian's understanding of web accessibility and Section 508 regulations. $^{17}$

A Voluntary Product Accessibility Template (VPAT) is a self-assessment document that vendors are required to complete only if they wish to sell their products to the federal government or any institution that chooses to require them. The quality of VPATs varies, but essentially they will list Section 508 standards and for each specify whether they fully or partially support it, do not support it, or if the standard is not applicable. There is then a space for the vendor to provide an explanation for limitations. Since these are voluntary self-assessments, these documents can sometimes be brief and incomplete, but even brief statements can be specific enough to relatively easily verify the claims of support.

Because libraries are portals to online content, including e-books, e-journals, databases, streaming media, and more, which are provided largely by third-party vendors, libraries face unique struggles when attempting to comply with federal regulations. Notions of equality and equal access are inherent to libraries and important for the maintenance of a democratic society, which makes accessibility within libraries' digital content a concerning ethics issue. ${ }^{18}$ Having little control over how ICT is designed, libraries still must figure out how to address accessibility needs within third-party ICT. In 2012, the Association of Research Libraries (ARL) Joint Task Force on Services to Patrons with Print Disabilities encouraged libraries to require publishers to implement industry best practices, comply with legal requirements for accessibility, include language in publisher and vendor contracts to address accessibility, and request documentation like VPATs. ${ }^{19}$ The task force's report was vital in the creation and direction of this study.

\section{Existing Literature and Studies}

As library professionals, we may often make assumptions of the accessibility of a third-party resource when the reality is that greater importance is placed on design of a product; accessibility components are either being added as special features or are being included once the design work is completed. ${ }^{20}$ Tatomir and Durrance conducted a study on the compatibility of thirty-two library databases with a set of guidelines for accessibility they called the Tatomir Accessibility Checklist. ${ }^{21}$ This list included checking the usability of these databases with a screen reader and braille renewable display. They found that 44 percent of the databases were inaccessible, with an additional 28 percent being only "marginally accessible," based on their criteria. This suggests major problems exist within vendor database platforms. ${ }^{22}$ 
Building on this research, Western Kentucky University Libraries conducted a study on VPATs from vendors to determine how accessible seventeen of their databases were. ${ }^{23}$ The university libraries ran an accessibility scan on those databases and compared the results with the vendors' VPATs, finding that the templates from the vendors were accurate about 80 percent of the time. Most of the vendors did not address the accessibility of Portable Document Format (PDF) files in their VPAT statements, though it was an important component of their services. Pertinent to this study, Western Kentucky's work looked for accessibility documentation on vendors' websites, and when one was not found, contacted the vendors requesting this information. This study was unique for targeting vendor-supplied VPATs rather than only examining the databases themselves or tutorials from vendors. As mentioned previously, this was only done for the libraries' main database vendors.

Mune and Agee published an article on the Ebooks Accessibility Project (EAP) funded by Affordable Learning Solutions at the California State University System. In this project, the researchers compared academic e-book platforms to e-reader platforms used for popular trade publications. They gathered data on the top sixteen library e-book vendors at San Jose State University based on patron usage and title and holdings counts. The results indicated that academic e-book platforms were less accessible than nonacademic platforms, largely because of hesitance in adopting the EPUB 3 format, which by default has superior navigation and document structure to PDF or HTML, common academic options. ${ }^{24}$ While this study focused solely on the accessibility of e-book materials, a method for contacting vendors used in the EAP study was adapted for the current study, applied at a larger scale. The EAP researchers attempted to locate the vendors' VPATs online, and they contacted the vendors at least twice to request a VPAT or other accessibility statement when none was located. It is noteworthy that of the sixteen vendors, all but one (94 percent) provided EAP with some form of accessibility documentation, though less than half (44 percent) had a VPAT available. ${ }^{25}$

Another study, by Joanne Oud, examined vendor-supplied database video tutorials. Half of the twenty-four vendors examined in Oud's study had tutorials in formats that were not accessible by keyboard or screen reader. This was largely because many of these tutorials were Flash-based. ${ }^{26}$ Shockwave Flash is neither accessible for persons with disabilities nor good for usability on modern browsers..$^{27}$ Oud's findings suggest that tutorial content would be more widely accessible if they were placed in YouTube or another platform that had transcripts and captions available. While the focus of the study was different from our own, it was similar in that Oud examined the accessibility of vendor materials apart from the journals and collections. Also, Oud noted that to make use of vendor tutorials, the website on which they are housed must likewise be accessible and the videos easy to find, but this is often not the case. ${ }^{28}$

Other studies suggest that vendor websites and platforms often impede access to information. Vendor platforms often have inaccessible PDFs, or the links to the full-text options are not easily located. DeLancey's study also found more than three-fourths of the vendors examined had images without alternative text and frames without titles, resulting in many users with visual impairments being left out of the content of these images and frames entirely. Of particular note, however, was the finding that not one of the vendors in this study had all forms - buttons, search boxes, and other browser navigation tools-labeled correctly, leaving the sites difficult to navigate. ${ }^{29}$ Beyond whether the information itself is accessible, the question inevitably arises, can 
the desired information even be reached? One way or another, the content on these platforms must be accessible and easy to find.

Part of the motivation behind the current study stems from what DeLancey put so well: "Only one vendor (out of seventeen), Project Muse, had a publicly available VPAT on their website, though 9 others supplied this documentation upon request in under a week." 30 The first step in improving accessibility of resources for our patrons is to discuss accessibility with them-to determine how accessible information resources are today and identify areas of need. If a VPAT or, minimally, any form of an accessibility statement is not easily discoverable on a vendor's website-even if it is available upon request-users with disabilities as well as enabled users are not able to benefit from this information. Are the vendors making it a priority in this case? Additionally, since 41 percent of the vendors DeLancey examined had no VPAT at all, what can be done before and aside from reaching out to vendors and stressing the importance of accessibility and of making statements on accessibility easy to find?

From legal responsibilities to the dismal reality of digital accessibility, the task of improving library service for patrons with disabilities is daunting, even with the empowering ethical drivers of the library value system. Ostergaard created "Strategies for Acquiring Accessible Electronic Information Sources," an incredible guide to begin creating a guide that helps librarians develop an accessibility plan informed by her own work committed to accessibility in her library. Steps 3 and 4 of Ostergaard's strategies are particularly relevant to the current study. Step 3, "Communicating with Vendors," involves inquiring about the accessibility of electronic products in addition to asking about any future plans for accessibility of their product and requesting VPATs or other vendor supplied accessibility documentation. Step 3 also recommends that librarians request vendors meet WCAG 2.0 best practices and to incorporate a clause in license agreements that clearly defines accessibility of their products as further demonstration of dedication to accessibility. Such communication, it is hoped, would also lead to improved product development. ${ }^{31}$

Once vendors are contacted, Ostergaard outlines in step 4 the importance of documenting vendor communication regarding digital accessibility and further suggests assigning a person or team to review information received. Ostergaard's library changed the name of their acquisitions budget to "access budget," reallocating a portion of their budget to review existing subscriptions, purchase accessible replacements, or in some cases, convert materials to an accessible format. The documentation review allowed the library to make informed decisions about collections and service availability on behalf of library users, but no mention was made of involving users in this process. The article provided a letter template that encompassed the aforementioned concepts and a request for assessment documentation, such as VPATs and official statements of compliance. The Ostergaard template served as a foundation for the language used in vendor communication for the current study, particularly the VPAT or other accessibility documentation request. ${ }^{32}$

There have been no studies that suggest a way to implement easily discoverable vendor accessibility documentation-even when said documentation is not readily available to the public on the vendors' sites. DeLancey suggested creating "an open repository for both vendor supplied documentation, and the results of any usability testing," but this was suggested for internal library use, not public dissemination. ${ }^{33}$ If this documentation is made more easily available, we can 
increase patron involvement in the discussion of accessibility of vendor-supplied library resources.

\section{RESEARCH METHODS}

Library-related research has focused the need for academic libraries to have accessible websites, in part to reach patrons who are participating in distance-education programs. ${ }^{34} \mathrm{~A}$ key component of a library's website is the materials it avails to patrons from vendors, like databases and database aggregators. Since, however, these materials are accessed via vendor platforms, they are outside the direct control of the library, making it more difficult to address accessibility concerns.

Some vendors have put forward significant effort in addressing accessibility needs. Some offer a built-in feature for text-to-speech for HTML files or provide documents in a variety of formats, including TXT and MP3 files, thereby offering a format that works well with common screenreading programs, or providing a sound file directly. This is of particular benefit to patrons with print disabilities. ${ }^{35}$ Other vendors, such as Ebook Central (formerly Ebrary), have worked to eliminate their Flash dependencies. This is recognized as a positive step toward making vendor content usable for all.

Streaming video and other nonprint-based library materials must also be accessible. A person with visual impairments may be able to hear the soundtrack of the video, but unless an accurate description is provided of what is being presented visually, he or she will miss out on such information, such as the names of those speaking. To complicate matters further, hearing impaired users of these databases will not be privy to what is verbalized unless accurate captions and transcripts, or an interpreter, is made available for the videos. Captions and transcripts are sometimes made available, but can easily be incomplete or incorrect. For example, Alexander Street Press provided closed captioning and transcripts for some collections but not others. Even when the captions or transcripts existed, as with a video we tested from Ethnographic Videos Online, it was of low quality, inscribing the word "object" as "old pics," "house" as "mess," and so forth. One vendor, Docuseek, had subtitles to translate from Spanish, but no closed captioning or transcript available. Audio-impaired users could not make full use of the video because the subtitles did not include all information presented in the sound track. (Transcripts can also be useful to visually impaired users using screen readers.) Films on Demand had better captions and transcripts, but did not include all the words on the screen in the transcript, such as the title. Regardless of the medium there are multiple ways to provide accessible versions, but they are seldom automatic.

Librarians must communicate the need for accessible digital files to vendors so they will prioritize it. As long as libraries-one of their main customer groups-accept their offerings whether accessible or not for persons with disabilities, vendors have no reason to put great effort into making these improvements. As Colker pointed out, commercial vendors are not required to comply with ADA regulations under Title II or Title III. ${ }^{36}$ Vendors may also face resource restrictions that hinder their ability to improve their platforms' accessibility. ${ }^{37}$ They are businesses, so it is natural that they would only commit a concerted effort to reformat and enhance their platforms and records if the benefits are expected to outweigh the costs; they must firstly be made aware of the issue, and know that it is important to libraries and their patrons. 
In much the same way as contracted workers constructing a physical space for a federal or federally funded agency must follow ADA standards for accessibility, so software vendors should be required to design virtual spaces to be accessible. This comparison was made by the Department of Education more than twenty years ago, and has the added benefit of greatly reducing the need for accommodation after the fact. ${ }^{38}$

According to Cardenes, "At a minimum, a public entity has a duty to solve barriers to information access that the public entity's purchasing choices create." 39 Oswal stressed the importance of integrating the blind user experience into the development of databases from the beginning, as well as finding steps useful for guiding library users after the fact. Merely following the rules set out in federal regulations is not enough to provide exemplary service to library patrons. The patrons as well must be involved in the process to fully address accessibility needs. ${ }^{40}$

\section{PROCESS AND FINDINGS}

The first objective of this study was to gain a better understanding of the accessibility of our library's vendor-provided digital resources through the review of vendor-provided accessibility documentation. The second objective of this study was to determine a method of increasing the visibility of accessibility documentation for the benefit of our users and to communicate to them our commitment to improving service to users with disabilities. With a digital collection consisting of 270 databases, more than 750,000 e-books and e-journals, and more than 12 million streaming media titles, it was difficult to identify an appropriate sample. We needed a collection that would best serve as an illustrative swatch of our library's digital holdings, and more importantly, a collection that would have the largest impact on our users. We also needed to establish a strategy for obtaining accessibility documentation regarding third-party content as well as create a delivery method for the VPATs and other documentation we discovered in the course of our study.

Similar to other institutions, our library maintains a directory of the most used and most useful databases on the library's homepage in the form of the A-Z List (http://libresources.wichita.edu/az.php). Determinations of usefulness are based on input from our reference librarians, who connect with user needs directly, whereas use comes from annual usage statistics compiled as per standard library procedures. Users can browse this directory by subject, search by title, and sort by database type (full-text, streaming media, etc.), and the A-Z list is a convenient place for users to begin their research. The directory also served as a convenient place to begin this study as it presented us with a sample that not only reflected the needs and habits of our patrons, but an excellent and diverse list of vendors to work with.

Beginning with a list of all subscribed databases (270 in 2016) exported directly from the A-Z List's backend, we sorted the list by vendor and determined that 74 vendors would be investigated. University materials indexed by the directory (i.e., institutional repository and LibGuides) were excluded from this study.

As visibility of accessibility documentation is of concern to this study, our investigation began by visiting the database or vendor's site and conducting a web search to obtain any information about accessibility. We were looking for mentions of the following keywords: "Section 508" or "Section 504," "W3" or "WCAG," "VPAT," “ADA," and simply “accessibility." Some sites were intuitive: thirty-four vendors (45 percent) had statements that were found online. Examples of commonly used documentation, which for the purposes of this study will be referred to as 
accessibility statements, included “Accessibility Policy," "Section 508 Compliance," or "Accessibility Statement." Of those thirty-four vendors who posted accessibility documentation online, eleven provided a VPAT or a link thereto in their accessibility statements.

If we could not find an accessibility statement on the site, vendors were contacted first via email requesting information and documentation regarding the accessibility of their product using a form letter inspired by the Ostergaard template. ${ }^{41}$ This email address was either found onlinelikely the "Contact Us" or technical support email links - or originated in the list of vendors' contacts maintained in the library management system if another contact could not be found. If a response was not received within thirty days, the vendors were contacted a second time, a suggestion gleaned from Mune and Agee's work. ${ }^{42}$ After all vendors included in the study had been contacted, any who did not provide a VPAT were contacted a final time with a specific request for a VPAT. For vendors who responded they could not provide a VPAT or other accessibility statement, we used a screenshot of their response as documentation. The form letter (see appendix A) used in the current study made it known to vendors that their response would be posted publicly for the benefit of our users. Twelve of the remaining vendors respond ed to our email inquiries with VPATs and seven vendors responded with other accessibility documentation.

\section{Results of Vendor Query for Accessibility Documentation}

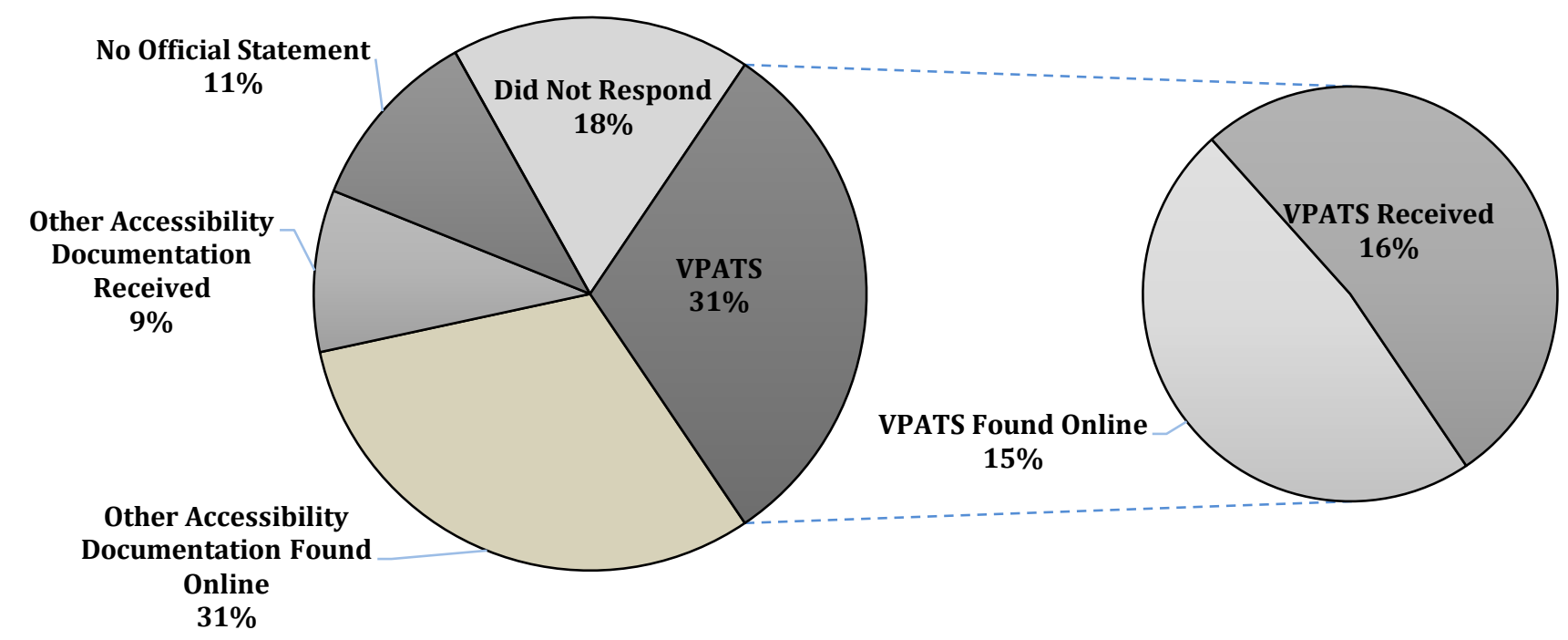

Figure 1. Results of vendor query for accessibility documentation.

In total, eleven VPATs (15 percent) were found online and VPATS from twelve vendors (16 percent) were received in response to our emailed request. Twenty-three vendors (31 percent) had other accessibility documentation available online, while seven vendors ( 9 percent) provided other accessibility documentation in response to email inquiries. Eight vendors (11 percent) 
responded they had no official statements or documentation to offer, and thirteen vendors (18 percent) did not respond (see figure 1).

With the documentation compiled, we needed to establish an appropriate delivery system that would make this accessibility information visible to library users and therefore further the accessibility efforts. Our collection cross-section, the A-Z List, was chosen because of its prominence in our library's online research presence as a suitable location to not only store but to convey this documentation to users. We created a clickable icon to be embedded into the databases' entries in our A-Z List created in LibGuides (a Springshare product). Clicking the icon would take the user to the vendor's statement page, directly to the VPAT, or to a page we created in LibGuides to store screen captures of vendor emails and VPATs we received as attachments. If a VPAT was available, we linked to it above any other documentation because VPATs present a more rigorous analysis of the accessibility of third-party-created ICT. LibGuides was determined to be a suitable place to house this documentation not only because it made the information easy to find for patrons, but also because Springshare built LibGuides in an increasingly accessible manner and has documented its efforts using VPATs for each product (see appendix B).

\section{FURTHER STUDY}

It is expected that some of the information provided by the vendors is incomplete or inaccurate, even despite their best efforts, so the information we provide to patrons from and about the vendors might at times lead our patrons astray. We briefly examined the VPATs acquired through this project to inform our work moving forward and found errors in at least half of them. Some vendors claimed that skip navigation was available when none was found, while another would have benefitted from it but said it was "not applicable." Others were too brief to be useful, as no explanations were given for their claims.

Building on this current research, we intend, in collaboration with patrons with disabilities, to further verify the accuracy of key statements made by vendors in their VPATs and other accessibility documentation. This analysis will give concrete feedback to vendors on how their sites could be further improved. As stated earlier, giving patrons access requires more than following a set of guidelines; it requires dialog to ensure their needs are fully met. ${ }^{43}$ It requires more than making the available documents accessible, but also testing the platform used to retrieve the documents for accessibility. As one author put it so well, "A lack of technological access is a solvable problem, but only if it is made a priority." 44 As vendors are not directly subject to enforcement of Section 508 and other statutes regarding accessibility of the products they provide to libraries, VPATs are truly voluntary. As such, the level of effort and detail of the product assessments are inconsistent and accuracy of the documentation is questionable. We intend to continue to be involved in the digital-accessibility initiative in part through our analysis of our digital-library presence, utilizing user input and expanding their role in improving the user experience. This would enable us to further improve our libraries' service to users with disabilities.

If we, as library professionals and institutions, stand together and each say our part, vendors will realize this is an important issue to address. Also, it is important that we, as service providers for the public good, act as a bridge between these vendors - who at times do not avail good service information to their customers-and the patrons we serve. It may be a small step, but providing links to the VPATs and other accessibility statements from vendors right where the patrons need 
them is an important step in meeting the patrons where they are and showing them help is available. We can show patrons we care and will work with them to improve the now limited accessibility of not only scholarly information itself, but even of the platforms in which they are housed. 


\section{APPENDIX A: ACCESSIBILITY DOCUMENTATION REQUEST EMAIL TEMPLATE}

Subject Line: VPAT Request

Thank you for the information you provided answering our inquiry regarding the accessibility of your electronic product. Wichita State University Libraries has set a goal of improving the accessibility of the electronic and information technology we provide to our patrons. In accordance with Section 504 of the Rehabilitation Act and Title II of the Americans with Disabilities Act, do you happen to have a Voluntary Product Accessibility Template (VPAT) available, or have you made plans to do further accessibility testing on your product? The VPAT documentation can be found on the U.S. Department of State Website:

http://www.state.gov/m/irm/impact/126343.htm. 
APPENDIX B: VPAT AND OTHER ACCESSIBILITY DOCUMENTATION URLS USED IN THE DATABASES A-Z LIST.

(List current as of October 20, 2017. Library subscriptions may have changed. Vendors may have updated URLs or added additional documentation since October 20. Research on this project is ongoing. Please see http://libresources.wichita.edu/az.php for a current list of vendor accessibility documentation.)

\begin{tabular}{|l|l|}
\hline Vendor & URLS \\
\hline $\begin{array}{l}\text { AAPG (American } \\
\text { Association of Petroleum } \\
\text { Geologists) }\end{array}$ & No accessibility documentation available \\
\hline ABC-CLIO & No response \\
\hline $\begin{array}{l}\text { ACLS (American Council of } \\
\text { Learned Societies) }\end{array}$ & $\begin{array}{l}\text { http://www.humanitiesebook.org/about/for-librarians/\#ada- } \\
\text { compliance-and-accessibility }\end{array}$ \\
\hline $\begin{array}{l}\text { ACM (Association of } \\
\text { Computing Machinery) }\end{array}$ & $\underline{\text { https://www.acm.org/accessibility }}$ \\
\hline $\begin{array}{l}\text { ACS (American Chemical } \\
\text { Society) }\end{array}$ & $\begin{array}{l}\text { https://www.acs.org/content/acs/en/accessibility- } \\
\text { statement.html }\end{array}$ \\
\hline Adam Matthew Digital & $\underline{\text { http://libresources.wichita.edu/c.php?g=583127\&p=4026332 }}$ \\
\hline $\begin{array}{l}\text { AIAA (American Institute of } \\
\text { Aeronautics \& Astronautics) }\end{array}$ & $\underline{\text { http://libresources.wichita.edu/ld.php?content id=32264954 }}$ \\
\hline Alexander Street Press & $\underline{\text { https://alexanderstreet.com/page/accessibility-statement }}$ \\
\hline $\begin{array}{l}\text { American Institute of } \\
\text { Physics }\end{array}$ & $\underline{\text { http://www.scitation.org/faqs }}$ \\
\hline $\begin{array}{l}\text { American Mathematical } \\
\text { Society }\end{array}$ & $\underline{\text { http://www.ams.org/about-us/VPAT-MathSciNet-2014-AMS.pdf }}$ \\
\hline $\begin{array}{l}\text { APA (American } \\
\text { Psychological Association) }\end{array}$ & $\underline{\text { http://www.apa.org/about/accessibility.aspx }}$ \\
\hline ASM International & No response \\
\hline $\begin{array}{l}\text { ASME (American Society of } \\
\text { Mechanical Engineers) }\end{array}$ & No accessibility documentation available \\
\hline ASTM & No accessibility documentation available \\
\hline BioOne & $\underline{\text { http://www.bioone.org/page/resources/accessibility }}$ \\
\hline Books 24x7 & $\underline{\text { https://documentation.skillsoft.com/bkb/qrc/AssistiveQRC.pdf }}$ \\
\hline Britannica & $\underline{\text { http://help.eb.com/bolae/Accessibility Policy.htm }}$ \\
\hline Business Expert Press & $\underline{\text { http://media2.proquest.com/documents/ebookcentral vpat.pdf }}$ \\
\hline Cabell's & No response \\
\hline $\begin{array}{l}\text { Cambridge Crystallographic } \\
\text { Data Centre }\end{array}$ & $\underline{\text { https://www.ccdc.cam.ac.uk/termsandconditions/ }}$ \\
\hline Cambridge University Press & $\underline{\text { http://www.cambridge.org/about-us/accessibility/ }}$ \\
\hline CAS & No accessibility documentation available \\
\hline $\begin{array}{l}\text { CLCD (Children's Literature } \\
\text { Comprehensive Database) }\end{array}$ & No response \\
\hline
\end{tabular}




\begin{tabular}{|c|c|}
\hline Conference Board & $\begin{array}{l}\text { http://www.conferenceboard.ca/accessibility/resources.aspx?As } \\
\text { pxAutoDetectCookieSupport=1 }\end{array}$ \\
\hline CQ Press & http://library.cqpress.com/cqresearcher/html/public/vpat.html \\
\hline Credo Reference & $\begin{array}{l}\text { https://credoreference.zendesk.com/hc/en- } \\
\text { us/articles/201429069-Accessibility }\end{array}$ \\
\hline dataZoa & $\begin{array}{l}\text { http://libresources.wichita.edu/AccessibilityStatements/DataZo } \\
\text { aVPAT }\end{array}$ \\
\hline Docuseek2 & $\begin{array}{l}\text { https://docuseek2.wikispaces.com/Section+508+Compliance+St } \\
\text { atement }\end{array}$ \\
\hline EBSCO & https://www.ebscohost.com/government/full-508-accessibility \\
\hline Ei Engineering Village & $\begin{array}{l}\text { https://www.elsevier.com/solutions/engineering- } \\
\text { village/features/accessibility }\end{array}$ \\
\hline Elsevier & $\begin{array}{l}\text { https://www.elsevier.com/solutions/sciencedirect/support/web } \\
\text {-accessibility }\end{array}$ \\
\hline Gale & https://support.gale.com/technical/618 \\
\hline Google & https://www.google.com/accessibility/initiatives-research.html \\
\hline HathiTrust & https://www.hathitrust.org/accessibility \\
\hline HeinOnline & https://www.wshein.com/accessibility/ \\
\hline IBISWorld & No response \\
\hline IEEE & https://www.ieee.org/accessibility statement.html \\
\hline Infobase Learning & $\begin{array}{l}\text { http://support.infobaselearning.com/index.php?/Tech Support/ } \\
\text { Knowledgebase/Article/View/1318/0/ada-usability-statement }\end{array}$ \\
\hline Infogroup & http://libresources.wichita.edu/c.php?g=583127\&p=4286285 \\
\hline Institute of Physics & http://iopscience.iop.org/page/accessibility \\
\hline InterDok & No response \\
\hline JSTOR & https://about.jstor.org/accessibility/ \\
\hline Kanopy & $\begin{array}{l}\text { https://help.kanopystreaming.com/hc/en- } \\
\text { us/articles/210691557-What-is-Kanopy-s-position-on- } \\
\text { accessibility- }\end{array}$ \\
\hline LexisNexis & http://www.lexisnexis.com/gsa/76/accessible.asp \\
\hline Library of Congress & https://www.congress.gov/accessibility \\
\hline Mergent & No accessibility documentation available \\
\hline National Academies Press & No response \\
\hline $\begin{array}{l}\text { National Library of } \\
\text { Medicine }\end{array}$ & https://www.nlm.nih.gov/accessibility.html \\
\hline Naxos & http://libresources.wichita.edu/c.php?g=583127\&p=4287131 \\
\hline NCJRS & https://www.justice.gov/accessibility/accessibility-information \\
\hline Newsbank & http://libresources.wichita.edu/c.php?g=583127\&p=4457078 \\
\hline OCLC & https://www.oclc.org/en/policies/accessibility.html \\
\hline Ovid & $\begin{array}{l}\text { http://ovidsupport.custhelp.com/app/answers/detail/a_id/590 } \\
\text { 9/ /is-the-ovid-interface-section-508-compliant\%3F }\end{array}$ \\
\hline Oxford University Press & $\begin{array}{l}\text { https://global.oup.com/academic/accessibility/?cc=us\&lang=en } \\
\underline{\text { \& }}\end{array}$ \\
\hline ProjectMUSE & https://muse.jhu.edu/accessibility \\
\hline
\end{tabular}




\begin{tabular}{|c|c|}
\hline ProQuest & $\begin{array}{l}\text { http://media2.proquest.com/documents/proquest academic vp } \\
\text { at.pdf, } \\
\text { http://media2.proquest.com/documents/ebookcentral vpat.pdf, }\end{array}$ \\
\hline Readex & $\begin{array}{l}\text { http://uniaccessig.org/lua/wp- } \\
\text { content/uploads/2014/11/Readex.pdf }\end{array}$ \\
\hline SAGE & https://us.sagepub.com/en-us/nam/accessibility-0 \\
\hline Salem Press & No response \\
\hline SBRnet & No response \\
\hline Springer & $\begin{array}{l}\text { https://github.com/springernature/vpat/blob/master/springerl } \\
\text { ink.md }\end{array}$ \\
\hline Standard \& Poor's & No response \\
\hline Swank & $\begin{array}{l}\text { No accessibility documentation available } \\
\text { (http://libresources.wichita.edu/AccessibilityStatements/SWAN } \\
\text { Kaccessibility) }\end{array}$ \\
\hline Taylor \& Francis & http://libresources.wichita.edu/c.php?g=583127\&p=4539268 \\
\hline Thomson Reuters & $\begin{array}{l}\text { https://clarivate.com/wp- } \\
\text { content/uploads/2018/02/PACR WoS } 5.27 \text { Jan-2018 v1.0.pdf, }\end{array}$ \\
\hline $\begin{array}{l}\text { US Department of } \\
\text { Commerce }\end{array}$ & http://osec.doc.gov/Accessibility/Accessibliity Statement.html \\
\hline $\begin{array}{l}\text { US Department of } \\
\text { Education }\end{array}$ & https://www2.ed.gov/notices/accessibility/index.html \\
\hline $\begin{array}{l}\text { US Government Printing } \\
\text { Office }\end{array}$ & https://www.gpo.gov/accessibility \\
\hline University of Chicago & No accessibility documentation available \\
\hline University of Michigan & https://www.press.umich.edu/about\#accessibility \\
\hline UpToDate & http://libresources.wichita.edu/c.php?g=583127\&p=4691631 \\
\hline ValueLine & $\begin{array}{l}\text { http://libresources.wichita.edu/AccessibilityStatements/ValueLi } \\
\text { neAccessibility }\end{array}$ \\
\hline $\begin{array}{l}\text { WRDS (Wharton Research } \\
\text { Data Services) }\end{array}$ & $\begin{array}{l}\text { https://wrds-www.wharton.upenn.edu/pages/wrds-508- } \\
\text { compliance/ }\end{array}$ \\
\hline Wiley & http://olabout.wiley.com/WileyCDA/Section/id-406157.html \\
\hline
\end{tabular}

\section{REFERENCES}

${ }^{1}$ Neil Savage, "Weaving the Web," Communications of the ACM 60, no. 6 (June 2017): 22.

${ }^{2}$ Ruth Colker, "The Americans with Disabilities Act is Outdated," Drake Law Review 63, no. 3 (2015): 799.

${ }^{3}$ Colker, "The Americans with Disabilities Act," 817; Joanne Oud, "Accessibility of Vendor-Created Database Tutorials for People with Disabilities," Information Technology and Libraries 35, no. 4 (2016): 13-14.

${ }^{4}$ Laura DeLancey and Kirsten Ostergaard, "Accessibility for Electronic Resources Librarians," Serials Librarian 71, no. 3-4 (2016): 181, https://doi.org/10.1080/0361526X.2016.1254134. 
${ }^{5}$ Americans with Disabilities Act of 1990, Pub. L. No. 101-336, 104 Stat. 327 (1990).

${ }^{6}$ Rehabilitation Act of 1973, Pub. L. No. 93-112, 87 Stat. 355 (1973).

${ }^{7}$ Discrimination on the Basis of Disability in Federally Assisted Programs and Activities, 77 Fed. Reg. 14,972 (March 14, 2012) (to be codified at 34 CFR pt. 104).

${ }^{8}$ DeLancey and Ostergaard, "Accessibility for Electronic Resources," 180.

${ }^{9}$ Architectural and Transportation Barriers Compliance Board, 65 Fed. Reg. 80,500, 80,524 (December 21, 2000) (to be codified at 36 CFR pt. 1194).

${ }^{10}$ Architectural and Transportation Barriers Compliance Board, 82 Fed. Reg. 5,790 (January 19, 2017) (to be codified at 36 CFR pt. 1193-1194).

${ }^{11} 29$ USC §794d, at 289 (2016).

${ }^{12}$ Architectural and Transportation Barriers Compliance Board, 82 Fed. Reg. 5,790, 5,791 (January 19, 2017) (to be codified at 36 CFR pt. 1193-1194).

${ }^{13}$ Paul T. Jaeger, "Section 508 Goes to the Library: Complying with Federal Legal Standards to Produce Accessible Electronic and Information Technology in Libraries," Information Technology and Disabilities 8, no. 2 (2002), http://link.galegroup.com/apps/doc/A207644357/AONE?u=9211haea\&sid=AONE\&xid=4c7f $\underline{77 d a}$.

${ }^{14}$ Architectural and Transportation Barriers Compliance Board, 82 Fed. Reg. 5,790, 5791 (January 19, 2017) (to be codified at 36 CFR pt. 1193-1194).

${ }^{15}$ Ben Caldwell et al., eds., "Web Content Accessibility Guidelines (WCAG) 2.0," last modified December 11, 2008, http://www.w3.org/TR/2008/REC-WCAG20-20081211/.

${ }^{16}$ DeLancey, Laura, "Assessing the Accuracy of Vendor-supplied Accessibility Documentation," Library Hi Tech 33, no. 1 (2015): 108.

${ }^{17}$ Ostergaard, Kirsten, "Accessibility from Scratch: One Library's Journey to Prioritize the Accessibility of Electronic Information Resources," Serials Librarian 69, no. 2 (2015): 159, https://doi.org/10.1080/0361526X.2015.1069777.

${ }^{18}$ Jaeger, "Section 508."

${ }^{19}$ Mary Case et al., eds., "Report of the ARL Joint Task Force on Services to Patrons with Print Disabilities," Association of Research Libraries, November 2, 2012, p. 29 , http://www.arl.org/storage/documents/publications/print-disabilities-tfreport02nov12.pdf.

${ }^{20}$ DeLancey and Ostergaard, “Accessibility for Electronic Resources," 180. 
${ }^{21}$ Jennifer Tatomir and Joan C. Durrance, "Overcoming the Information Gap: Measuring the Accessibility of Library Databases to Adaptive Technology Users," Library Hi Tech 28, no. 4 (2010): 581, https://doi.org/10.1108/07378831011096240.

22 Tatomir and Durrance, “Overcoming the Information Gap,” 584.

${ }^{23}$ DeLancey, "Assessing the Accuracy," 104-5.

${ }^{24}$ Christina Mune and Ann Agee, "Are E-books for Everyone? An Evaluation of Academic E-book Platforms' Accessibility Features," Journal of Electronic Resources Librarianship 28, no. 3 (2016): 172-75, https://doi.org/10.1080/1941126X.2016.1200927.

${ }^{25}$ Mune and Agee, “Are E-books for Everyone?,” 175.

${ }^{26}$ Joanne Oud, "Accessibility of Vendor-Created Database Tutorials for People with Disabilities," Information Technology and Libraries 35, no. 4 (2016): 12, https://doi.org/10.6017/ital.v35i4.9469.

${ }^{27}$ Mark Hachman, “Tested: How Flash Destroys Your Browser's Performance,” PC World, August 7, 2015, https://www.pcworld.com/article/2960741/browsers/tested-how-flash-destroysyour-browsers-performance.html.

${ }^{28}$ Oud, “Accessibility of Vendor-Created Database Tutorials,” 12.

${ }^{29}$ DeLancey, "Assessing the Accuracy," 106-7.

30 DeLancey, “Assessing the Accuracy,” 105.

${ }^{31}$ Kirsten Ostergaard, "Accessibility from Scratch: One Library's Journey to Prioritize the Accessibility of Electronic Information Resources," Serials Librarian 69, no. 2 (2015): 162-65, https://doi.org/10.1080/0361526X.2015.1069777.

32 Ostergaard, “Accessibility from Scratch.” 164

33 DeLancey, “Assessing the Accuracy,” 111.

${ }^{34}$ Cynthia Guyer and Michelle Uzeta, "Assistive Technology Obligations for Postsecondary Education Institutions," Journal of Access Services 6, no. 1/2 (2009): 29; Oud, "Accessibility of Vendor-Created Database Tutorials," 7.

${ }^{35}$ Mune and Agee, “Are E-books for Everyone?,” 173.

${ }^{36}$ Colker, “The Americans with Disabilities Act," 792-93.

${ }^{37}$ DeLancey, “Assessing the Accuracy,” 107.

${ }^{38}$ Colker, "The Americans with Disabilities Act," 814; Mune and Agee, "Are E-books for Everyone?," 182. 
${ }^{39}$ Adriana Cardenes to Dr. James Rosser, April 7, 1997, private collection, quoted in Colker, "The Americans with Disabilities Act is Outdated," 815.

40 Sushil K. Oswal, "Access to Digital Library Databases in Higher Education: Design Problems and Infrastructural Gaps,” Work 48, no. 3 (2014): 316.

${ }^{41}$ Ostergaard, “Accessibility from Scratch," 164.

42 Mune and Agee, “Are E-books for Everyone?," 175.

43 DeLancey, “Assessing the Accuracy," 108; Mune and Agee, “Are E-books for Everyone?,” 181.

${ }^{44}$ Colker, "The Americans with Disabilities Act," 817. 